\title{
Microstructural Evolution of Inconel 625 and Inconel 686CPT Weld Metal for Clad Carbon Steel Linepipe Joints - A Comparator Study
}

\author{
The effect of iron dilution on the elemental segregation of alloying elements in nickel \\ based filler metals.
}

\begin{abstract}
C.A Maltin ${ }^{1}$, A.M Galloway ${ }^{2}$ and M. Mweemba ${ }^{3}$
1 Mechanical and Aerospace Engineering, Mechanical and Aerospace Engineering, Level 8, James Weir Building, 75 Montrose Street, Glasgow, G1 1XJ. Email: charles.maltin.2013@uni.strath.ac.uk 2 Mechanical and Aerospace Engineering, Mechanical and Aerospace Engineering, Level 8, James Weir Building, 75 Montrose Street, Glasgow, G1 1XJ Email: alex.galloway@strath.ac.uk 3 Specialist Engineer Welding and Materials Department, Subsea 7, East Campus, Prospect Road, Arnhall Business Park, Westhill, Aberdeenshire, AB32 6FE, Scotland. Email: martin.mweemba@subsea7.com
\end{abstract}

Corresponding Author: C.A. Maltin Mechanical and Aerospace Engineering, Level 8, James Weir Building, 75 Montrose Street, Glasgow, G1 1XJ. Email: charles.maltin.2013@uni.strath.ac.uk Telephone: +44 (0)1415484851

\begin{abstract}
Microstructural evolution of Inconel 625 and Inconel 686CPT filler metals, used for the fusion welding of clad carbon steel linepipe, has been investigated and compared. The effects of iron dilution from the linepipe parent material on the elemental segregation potential of the filler metal chemistry has been considered. The results obtained suggest that, in Inconel 686CPT weld metal, the segregation of tungsten is a function of the level of iron dilution from the parent material. The data presented suggest that the incoherent phase precipitated in the Inconel 686CPT weld metal has a morphology that is dependent on tungsten enrichment and, therefore, iron dilution. Furthermore, in the same weld metal a continuous network of finer precipitates was observed. The Charpy impact toughness of each filler metal was evaluated and the results highlighted the superior impact toughness of the Inconel 625 weld metal over that of Inconel $686 \mathrm{CPT}$.
\end{abstract}

Keywords: Nickel base alloys; Solidification; Dissimilar Weld; Clad; Element Segregation; GTAW 


\section{Introduction}

1. Carbon steel linepipe internally clad with a corrosion resistant alloy (CRA) is used in the offshore oil and gas industry as a cost effective means for the transport of corrosive product. To avoid localised corrosion within the weld zone of the CRA clad linepipe, a highly alloyed nickel based filler metal is utilised. However in addition to providing a superior corrosion resistance to that of the CRA layer, the nickel based filler metal selected must demonstrate overmatching properties in terms of yield strength and toughness.

2. A recently developed nickel based superalloy being utilised for the dissimilar fusion welding of bi-metallic offshore pipelines is INCO-WELD 686CPT (IN686CPT). IN686CPT is manufactured for its superior corrosion resistance and has sufficiently high yield strength to overmatch high grade carbon steel linepipe. A recently developed nickel based superalloy being utilised for the dissimilar fusion welding of bi-metallic offshore pipelines is INCO-WELD 686CPT (IN686CPT). IN686CPT is manufactured for its superior corrosion resistance and has sufficiently high yield strength to overmatch high grade carbon steel linepipe. However, the microstructural evolution of the weld metal upon solidification is not well documented and there has been no investigation into the segregation behaviour of alloying additions when used for dissimilar weld applications. In the present study, the microstructural evolution of weld metal produced by IN686CPT is compared to that of Inconel 625 (IN625), whose solidification behaviour has been widely reported [1-10].

3. It is worth noting that the majority of solid solution strengthened nickel base alloys are developed to be singe phase, face centred cubic (FCC) austenite $(\gamma)$ [11]. However, due to solidification mechanisms and certain alloys exhibiting elemental compositions that are beyond the solubility limit, for the metal matrix in which they are solutioned, secondary brittle phases may be formed [11].

4. Welding presents an additional metallurgical challenge associated with nickel base superalloys; due to the variable parameters which may be employed and an elevated cooling rate (relative to equilibrium cooling) the microstructure is highly changeable and therefore difficult to predict. Given that both the mechanical and corrosion properties of the weld metal are governed by the microstructure and its evolution upon solidification, there have been extensive studies into the behaviour of nickel base superalloy weld metals and the effect of their alloying additions on the solidification behaviour [1-5, 11-14]. 
5. In terms of predicting the likely phases to be precipitated, it has been reported $[4,5$, $12,15]$ that tendency for certain alloying additions to segregate to either the dendrite core or the interdendritic liquid during solidification is governed by the segregation potential, associated with that element. This tendency for segregation may be numerically quantified with the segregation coefficient, $k$, [3-5] which is derived from the Scheil equation $[11,16]$ for the modelling of solute redistribution - where there is negligible solid diffusivity as in the case for the alloying additions with nickel based superalloys.

6. Based upon the Scheil equation, it is evident that the extent of segregation of alloying additions may be determined entirely upon the value of $k$ associated with the element of interest [11]. Elements which have a value of $k<1$ demonstrate a tendency to segregate to the interdendritic liquid; whereas those with a value of $k>1$ segregate to the dendrite core $[3,11]$. Elements with potential to segregate to the interdendritic region $(k<1)$ are the last to solidify and, with the accelerated cooling rate experienced during fusion welding, are forced to do so in a eutectic reaction in which the transformation to a brittle TCP phase or carbide is facilitated [3].

7. This phenomenon is well documented in the literature; Maguire et al. [3] presented a study investigating the microstructural evolution of Alloys 625 and 718 and their newly developed variants in which the effect of chemistry upon the phases precipitated was considered. Maguire et al. [3] noted that although the $\mathrm{Nb}$ additions were key to the development of these alloys strength, it also segregates to the interdendritic liquid during solidification where it forms either carbides of the form $\mathrm{MC}$ or a TCP phase known as Laves [3]. Molybdenum was also noted as both promoting the segregation of the $\mathrm{Nb}$ as well as forming within the Laves phase itself [3].

8. Similar observations were made in various other publications using IN625 where both Laves phase and $\mathrm{NbC}$ were formed during solidification [1, 2, 4-10]. Once again, Laves phase was found to be enriched by the both $\mathrm{Nb}$ and Mo. Within a study by DuPont et al. [4], sigma phase was observed in IN622 welds and its composition was noted to be enriched with both $\mathrm{Cr}$ and Mo.

9. As previously noted, due to the relatively recent development of IN686CPT the microstructural evolution is not well documented. Furthermore, the dissimilar nature of the weld investigated in the present study creates an additional consideration in terms of iron dilution from the parent material. DuPont et al. [4] reported that the iron dilution from a super duplex parent material may be causing an increased segregation potential of the elements within the IN625 weld metal. They demonstrated that the segregation of $\mathrm{Mo}$ and $\mathrm{Nb}$ increases with increasing iron dilution from the parent material [4, 5]. In terms of composition, IN625 and IN686CPT weld metal are relatively similar with the only major differences being higher Mo contents in IN686CPT as well as the addition of tungsten (W). The surrounding literature has demonstrated a significant lack of documentation and understanding regarding the behaviour of $\mathrm{W}$ during solidification of nickel based weld metals [11]. 
10. However, it has been stated that despite the behaviour of $\mathrm{W}$ not being well understood, it is not thought to demonstrate a segregation tendency when used as a solid solutioning element [11].

11. This apparent lack of segregation behaviour is likely based upon the reported segregation coefficients for tungsten within the same source $(k \approx 1)$ [11], however, these values do not account for the interaction between $W$ and Fe. Adopting a similar approach as DuPont et al. [4] and utilising binary alloy phase diagrams to postulate the effect of iron dilution on elemental segregation: it is reported that the solubility of $\mathrm{W}$ in $\gamma$-Ni is up to $39.9 \mathrm{wt} .-\%$ whereas in $\gamma$-Fe $\mathrm{W}$ is insoluble [17].

12. The interaction between $\mathrm{Fe}$ and $\mathrm{W}$ was also highlighted by Perricone et al. [15] where calculated Ni-Cr-Mo pseudo-ternary liquidus surfaces demonstrated the effect of including both $\mathrm{Fe}$ and $\mathrm{W}$ on the stabilisation of the $\mathrm{P}$ phase [15].

13. The aim of the present study was thus to evaluate the hypothesis that since iron will segregate to the dendrite core $(k>1)[4,5]$ and tungsten is insoluble in $\gamma$-Fe [17] it will be forced into the interdendritic liquid. Hence as solidification progresses, the liquid phase becomes richer in both tungsten and molybdenum before completion where a eutectic type reaction occurs and a TCP phase is precipitated. This theory is supported by DuPont et al. [11], who state that:

"...with higher Mo additions, combined with the presence of Fe and W, TCP phases typically cannot be avoided in the fusion zone during solidification..."

14. Hence it is important to characterise the microstructural evolution of IN686CPT, to determine if deleterious eutectic type phases are formed as the result of elemental segregation in the weld metal, and to evaluate the segregation potential of tungsten as a function of iron dilution from the parent material. The effect of the microstructural evolution on the mechanical properties was evaluated using Charpy $\checkmark$ notch impact testing. 


\section{Experimental Methods}

15. Welds were produced using a base material of 12" API $5 \mathrm{~L}$ X65 carbon steel linepipe of thickness $19 \mathrm{~mm}$, internally clad with $3 \mathrm{~mm}$ of alloy $316 \mathrm{~L}$. One side of the linepipe was welded using IN625 and the other using IN686CPT.

16. In both cases, the manual gas tungsten arc welding (GTAW) process was used to produce the weldments. In order to generate a variation in iron dilution, the weld geometry was arranged with a $45^{\circ}$ weld prep on one side of the joint and a $90^{\circ}$ weld prep on the other (Figure 1). Both IN625 and IN686CPT wires used were of $2.4 \mathrm{~mm}$ diameter and all welds were deposited in the $2 \mathrm{G}$ position. TVC ALX II Arc Logging equipment was used to capture the weld parameters allowing the heat input to be calculated using equation (1):

$$
\text { HeatInput }=\frac{\text { Voltage } \times \text { Current }}{\text { TravelSpeed }}
$$

17. Average heat inputs for IN625 in the root, hot pass, fill and cap were 1.98, 1.361 .29 and $1.02 \mathrm{~kJ} / \mathrm{mm}$ respectively. For IN686CPT average heat inputs in the root, hot pass, fill and cap were 1.96, 1.1, 1.08 and $1.2 \mathrm{~kJ} / \mathrm{mm}$ respectively. The pre-weld chemical compositions of the two alloy wires are given in Table 1. Macro sections were cut from both the IN625 and the IN686CPT side of the weld. They were polished to a final grit of $1 \mu \mathrm{m}$ and etched with a $5 \%$ electrolytic Nital solution (Figure 1).

\begin{tabular}{|c|c|c|c|c|c|c|c|c|c|c|c|c|c|c|c|}
\hline \multirow[t]{2}{*}{ Alloy } & \multicolumn{15}{|c|}{ Composition (wt-\%) } \\
\hline & $\mathrm{Ni}$ & $\mathrm{Cr}$ & Mo & $\mathbf{W}$ & Al & Mn & $\mathrm{Fe}$ & $\mathrm{Ti}$ & $\mathbf{S i}$ & Co & NbTa & $\mathrm{Cu}$ & C & S & $\mathbf{P}$ \\
\hline IN686CPT & 58.91 & 20.4 & 16.13 & 3.71 & 0.32 & 0.22 & 0.16 & 0.05 & 0.031 & 0.03 & 0.01 & $<0.01$ & 0.004 & 0.001 & $<0.001$ \\
\hline IN625 & 63.17 & 22 & 9.6 & - & 0.3 & 0.2 & 0.5 & 0.3 & 0.05 & 0.05 & 3.8 & 0.01 & 0.01 & 0.001 & 0.001 \\
\hline
\end{tabular}

Table 1: Pre-weld composition of IN686CPT and IN625

18. The evolved microstructure of each weld was characterised using both an Olympus GX51 light microscope with a polarising lens and differential interference contrast (DIC) capabilities, and a HITACHI S-3700 tungsten filament scanning electron microscope. For phase identification and quantitative element analysis, energy dispersive X-ray spectroscopy (EDS) was employed using the Oxford Instuments Inca 350 with an $80 \mathrm{~mm}$ X-Max detector fitted to the SEM. Iron dilution was quantified using standard SEM techniques; a HITACHI SU-6600 field emission SEM equipped with EDS was used to analyse the elemental composition at various points along a reference line marked onto the macro section. At each point, an accelerating voltage of $20 \mathrm{kV}$ and a working distance of $10 \mathrm{~mm}$ was used to measure the wt- $\%$ of iron; the iron dilution in the weld metal was calculated using equation (2):

$$
D=\frac{F e_{a}-F e_{f m}}{F e_{p m}-F e_{f m}} x 100
$$


19. Where $D$ is the iron dilution and $F e_{a}, \mathrm{Fe}_{f m}$ and $\mathrm{Fe} p m$ are the iron contents in wt-\% at the point of analysis, the filler metal and the parent metal respectively.

20. EDS 'line scans' were used to calculate both the segregation potential of alloying additions and relative enrichment of precipitated phases. For investigation of the segregation potential of tungsten as a function of iron dilution, analysis points were plotted along a line covering dendrite cores and their corresponding interdendritic regions in three distinct areas of $45^{\circ}$ Fusion Line (FL), weld metal centre line (WM) and $90^{\circ} \mathrm{FL}$. For precipitate enrichment studies, 3 precipitates, of similar morphology, from each of the three areas used in dendrite scanning were analysed. SEM parameters were kept constant with a magnification of $x 4.00 \mathrm{k}$, an accelerating voltage of $20 \mathrm{kV}$ and a working distance of $10 \mathrm{~mm}$. It was ensured that each of the line scans had 12 analysis points and a minimum of 3 points were on the precipitate.

21. Electron backscatter diffraction (EBSD) was employed for grain sizing and orientation studies, and to determine the level of crystallographic misorientation within the matrix. A HITACHI SU-6600 field emission SEM equipped with an Oxford Instruments HKL NordlysF EBSD camera was utilised for acquiring electron backscatter diffraction patterns. HKL Fast Acquisition and the CHANNEL 5 software packages were used for postprocessing and grain mapping.

22. X-Ray Diffraction (XRD) was utilised for determination of the lattice parameters of the weld metal unit cell. In the present study, a BRUKER D8 ADVANCE with DAVINCI X-Ray Diffractometer was utilised in conjunction with the DIFFRAC.SUITE EVA for postprocessing and peak matching. The scan employed was performed between a 2 Theta range of $20^{\circ}$ and $100^{\circ}$ with a step size of approximately $0.02^{\circ}$ and counting at each step for 4 seconds; these parameters were selected since reasonable results were achieved by Rai et al. [18] when using XRD on Inconel 625. The X-Ray generator power was set at $1.6 \mathrm{~kW}(40 \mathrm{kV}$ and $40 \mathrm{~mA})$ and $\mathrm{Cu}$ Ka radiation was used.

23. Charpy $V$ notch specimens were taken from both the IN625 and IN686CPT sides of the weld, and made in accordance with BS EN 148 and BS EN ISO 9016. Notches were cut perpendicular to the pipe surface. A total of 8 sets of Charpy $V$ notch specimens were produced for each filler metal type (each set consisting of 3 specimens), 4 sets were notched on the $90^{\circ} \mathrm{FL}, 2$ sets were notched on the $45^{\circ} \mathrm{FL}$ and 2 sets were notched in the weld metal centre line (WMCL). With regards to the $90^{\circ} \mathrm{FL}$, the notch was located with a minor bias towards the weld metal in order to encourage fracture through this material. For the $45^{\circ} \mathrm{FL}$, the notch was located such that it was at the midpoint between the point of fusion on the upper and lower sides of the specimen as shown in Figure 2.

24. Twice as many sets were produced for the $90^{\circ} \mathrm{FL}$, as the results of those notched on the $45^{\circ} \mathrm{FL}$ would have their properties masked due to a combination of both filler metal and parent material. Furthermore, by using the $90^{\circ} \mathrm{FL}$, it was felt that the properties of the filler metal could be better sampled and a more reliable indication of the formation of deleterious precipitates demonstrated. 
25. Certain fractured Charpy specimens were selected for examination and imaging using scanning electron microscopy, again a HITACHI S-3700 tungsten filament SEM was employed. In order to examine precipitation on the fractured surface, electrolytic oxalic acid was used.

\section{Results and Discussion}

\section{Light Optical Microscopy (LOM)}

26. In both IN625 and IN686CPT welds, the dendrites were more densely packed in areas around the fusion lines as a result of higher cooling rates [13]. It has been suggested that the compositional difference between the weld metal and the parent material increases the cooling rate and hence the density of dendrite packing [13] at the fusion lines. In the present study eutectic type precipitates, assumed to be either a TCP or carbide phase, were observed in both the IN625 and IN686CPT welds. However, there were significant differences in the morphology and quantity observed.

27. The $45^{\circ} \mathrm{FL}$ of the IN686CPT weld (Figure $3 \mathrm{~A}$ ), shows a significant volume fraction of eutectic type precipitate in the interdendritic region, and the precipitates observed appear to be continuous in morphology.

28. Finer precipitation was also observed in the interdendritic region of the IN686CPT weld metal on the $45^{\circ} \mathrm{FL}$ (Figure $3 \mathrm{~A}$ ), which was speculated to be a carbide phase. It is reported that carbides can, in some instances, be used to 'pin' grain boundaries and thus provide higher values of tensile strength [19]. However, in this instance, the precipitation was observed to be a continuous film along the grain boundaries, known to be deleterious to mechanical properties [19]. In addition, the film precipitation appears to connect the larger eutectic type precipitates together, providing a path of least resistance for crack propagation, through a network of brittle precipitates.

29. The centre line of the weld metal and the $90^{\circ} \mathrm{FL}$ were investigated (Figures $3 \mathrm{~B}$ and $3 \mathrm{C}$ respectively). In the region around the $90^{\circ} \mathrm{FL}$ similar precipitates are observed, however they appear to be less continuous in nature and the film precipitation is reduced.

30. In the centreline of the weld metal the dendrite coring is far less pronounced, most likely due to a slower cooling rate. The phase precipitated is globular in morphology as opposed to continuous when precipitated at the fusion lines. 
31. The $45^{\circ} \mathrm{FL}, \mathrm{WMCL}$ and $90^{\circ} \mathrm{FL}$ were also investigated in the IN625 weld (Figures $4 \mathrm{~A}, 4 \mathrm{~B}$ and $4 \mathrm{C}$ respectively) and provided evidence to suggest that the precipitated phase is consistent in each of the three regions. A globular as opposed to continuous morphology was observed across the body of the weld - the morphology did not appear to be dependent upon region of analysis. Furthermore, the analysis conducted appeared to demonstrate a lower volume fraction of precipitated phase.

32. Therefore the data acquired from the light microscopy suggests that dilution from the parent material has a more significant influence on IN686CPT than on IN625; with the morphology and volume fraction of precipitated phase remaining relatively consistent across the weld in IN625 and displaying significant variability in IN686CPT.

33. Furthermore, initial observations from the light microscopy indicate that the dilution from the parent material is also leading to a change in the morphology of the phase precipitated. In addition, with a high carbon content as a result of dilution from the CMn steel parent material, the observed film precipitation has been speculated to be a network of carbide precipitates.

Iron Dilution

34. The results obtained in the iron dilution study are shown in Figure 5.

35. As the $45^{\circ} \mathrm{FL}$ is approached, the iron dilution is increased significantly above that of the $90^{\circ} \mathrm{FL}$. In the centre of the weld, despite lower values, dilution has still occurred with an average of approximately $5 \mathrm{wt}$-\% compared to the pre-weld composition of the filler metal at $0.16 \mathrm{wt}-\%$ iron. Therefore, any segregation potential of tungsten that is a function of the iron dilution would be reduced across the centre of the weld but would not be eliminated completely.

Element Segregation and TCP/Carbide Phase Formation

36. Incoherent precipitates were observed in both IN625 and IN686CPT welds, the typical morphologies of which are given in Figures $6 \mathrm{~A}$ and $6 \mathrm{~B}$ respectively.

37. The type of TCP and carbide phases precipitated in IN625 are well documented to be the Laves and $\mathrm{NbC}$ phases respectively [1-10] and hence these shall not be discussed in detail here. The result of an initial EDS analysis of the phase precipitated in the IN686CPT weld metal demonstrated it was enriched in both molybdenum and tungsten, while being depleted in nickel and iron as shown in Figures 7A and 7B. It is worth noting at this stage that Fe has been omitted from the relative enrichment plot since its magnitude is much greater than the other elements, as a result of dilution from the parent material and not as a result of its segregation into the precipitated phase.

38. The segregation potential of tungsten as a function of iron dilution was also investigated via EDS analysis. Figure 8 shows the wt-\% of tungsten at each of these analysis points for the three regions. 
39. Variation in tungsten content, and hence the difference between the 'peaks' and the 'troughs', is dependent on the location of the analysis (Figure 8). At the $45^{\circ} \mathrm{FL}$, where the dilution of iron is highest, the variation of tungsten between the dendrite core and interdendritic region is most significant. In contrast, in the centre of the weld metal the variation is minimal, although segregation of tungsten is still occurring, and may be attributed to the small iron dilution (Figure 5) discussed previously. At the $90^{\circ}$ $\mathrm{FL}$, tungsten segregation is evident although it is not as significant as on the $45^{\circ}$ side; this further supports the concept that the segregation potential of tungsten is the result of iron dilution.

40. Based on the dendrite core and interdendritic compositions determined by EDS, the segregation coefficient of tungsten may be calculated using equation (3):

$$
k=\frac{X_{\text {DendriteCore }}}{X_{\text {Interdendritic }}}
$$

41. Where $k$ is the elemental segregation coefficient and $X$ is the wt- $\%$ of the element of interest in the dendrite core or interdendritic region. Values of $k$ were obtained for each of the three regions analysed above and the results averaged. As expected, the lowest value of $k$ and hence where the segregation behaviour is most pronounced was 0.86 and obtained from the $45^{\circ}$ side of the weld. The values obtained in the centre line and $90^{\circ}$ side were 0.96 and 0.88 respectively. Therefore, the $k$ value assigned to tungsten cannot be assumed to be 1 in a dissimilar weld of this nature, since it is a function of the iron dilution. This is contrary to the statement of DuPont et al. [11] that although the behaviour of tungsten is not well understood is shows little segregation potential in nickel based alloys.

42. EDS analysis was also used to demonstrate that tungsten enrichment, as a result of iron dilution, is altering the morphology of the phase precipitated. To calculate relative enrichment the pre-weld tungsten content (Table 1) was used and the results plotted for each of the precipitate line scans at the $45^{\circ} \mathrm{FL}$, weld metal centreline and $90^{\circ} \mathrm{FL}$ (Figure 9)

43. The most significant enrichment was in the $45^{\circ} \mathrm{FL}$ precipitate analysis where all values exceed an enrichment of 1.3. This effect was reduced in the $90^{\circ} \mathrm{FL}$ and further reduced in the weld metal centre line. Some enrichment was noted in the weld metal centre line; however this is to be expected given the observed iron dilution (Figure 5). Moreover, all of the precipitates analysed were of similar continuous type morphology, likely resulting from tungsten enrichment. This was demonstrated by conducting similar analysis on a precipitate of globular morphology from the centre line, cap region of the weld as shown in Figure 10. The results show that the globular type precipitate has negligible tungsten enrichment, measuring a tungsten content approximately equal to that of the pre-weld composition. However, molybdenum enrichment is still significant, thus the data suggests that the continuous type morphology observed in IN686CPT weld metal is associated with 
the segregation and following enrichment of tungsten in the eutectic type precipitate formed.

44. Similar enrichment calculations were also conducted for molybdenum to further support the claims that molybdenum was present in all precipitates analysed, the results are presented in Figure 11. It is worth noting that molybdenum segregation is known to exhibit some form of relation to iron dilution $[4,5]$, again due to a decreased solubility in the $y$-Fe matrix $[4,5]$.

45. Although the most significant molybdenum enrichment was observed in the precipitates found on the $45^{\circ} \mathrm{FL}$ there was still considerable enrichment in those of the weld metal centreline. As previously noted, in the precipitate of globular morphology, molybdenum enrichment was substantial with values of up to 1.6 being recorded. This behaviour of molybdenum is the result of its inherent segregation potential to the interdendritic liquid [1-8, 10,12]. Hence, it is suggested that although iron dilution from the parent material may offer increased segregation behaviour as demonstrated elsewhere $[4,5]$ it is not a prerequisite and thus incoherent phases enriched in molybdenum will form regardless of parent material dilution.

46. The combination of SEM and EDS analysis has provided substantial evidence to suggest that not only is the segregation potential of tungsten to the interdendritic liquid a function of iron dilution from the parent material in a dissimilar weld, it also has an effect on the morphology of the incoherent phase that is precipitated. It is proposed that the enrichment of tungsten causes the precipitate morphology to become continuous which, coupled with the network of fine precipitation as observed in light microscopy, is likely to present a path of least resistance for crack propagation and ultimately failure. 


\section{Electron Backscatter Diffraction Analysis}

47. Since a higher volume fraction of precipitate was observed on the $45^{\circ} \mathrm{FL}$ side of the weld, electron backscatter diffraction (EBSD) studies were carried out primarily in this region. Initially, a relatively large area of the weld metal was mapped, using a step size of $0.504 \mu \mathrm{m}$, in order to characterise the prevailing grain size within the weld. The results are presented in Figure 12.

48. Upon further inspection of Figure 12, it was evident that there was significant disparity amongst the grains observed. The majority of grains within the map are relatively large, with an approximate width of $42 \mu \mathrm{m}$, however, there are those which are significantly smaller and have vastly different morphologies relative to the rest of the mapped area. It is postulated herein that these apparently smaller grains of different morphology are the precipitates which have been observed in SEM and LOM studies. This speculation is further substantiated by the observation that within these smaller regions of different morphology, the software has assigned various false colours; the colours are used to differentiate between different grains which, in turn, is based upon the level of crystallographic misorientation. Hence it is implied that there is a high level of misorientation in these regions which is typical of an incoherent phase within a matrix $[20,21]$ and often associated elemental segregation [21].

49. The same region of the $45^{\circ} \mathrm{FL}$ side of the weld was analysed using EBSD but in this instance, at a higher magnification and thus a smaller step size, $0.2313 \mu \mathrm{m}$ the results are provided in Figure 13. Similar observations were again made, where although the majority of the mapped area consisted of large grains of similar orientation, there were smaller regions of significantly different morphologies that have been mapped as separate grains. Moreover, the data again suggests that these smaller regions are associated with incoherent phase precipitation since there is a high crystallographic misorientation associated with them.

50. It should be noted that attempts were made to utilise combined EDS and EBSD to demonstrate a chemical analysis of the likely precipitates observed. However, due to EBSD being a surface technique (concerning only the surface nanometers of the material) and requiring a tilt angle of approximately $70^{\circ}$; any surface topography may lead to shadowing of electron backscatter patterns (EBSPs) and hence an insufficient level of indexing. Therefore, the surface etch required in order to observe the surface regions was not feasible and thus EDS could not be employed accurately. 


\section{$X$-Ray Diffraction}

51. X-Ray Diffraction (XRD) was conducted across the body of the weld metal, between a 2Theta angle of $20^{\circ}$ and $100^{\circ}$, in order to develop a characterisation of the material and to highlight any variation in crystallographic structure the collimator was removed such that a significantly larger area of weld metal was analysed. The results obtained were post processed using the associated software; post processing consisted of a 'Peak Scan' where the peaks were identified and the K $\alpha 2$ background radiation removed. Furthermore, the peaks obtained in the scan were matched using the database software. The results are provided in Figures 14A and 14B where the red peak lines indicate a peak obtained from the scan of the weld metal and the blue peak lines indicate a peak of the matched database result.

52. The database matched a number of the peaks identified in the present study as corresponding to those associated with Hastelloy® C-276 based upon research conducted by Ahmad et al. [22]. Given that the composition of these two alloys are very similar, this result is perhaps unsurprising. Furthermore, the disparity in the actual peak locations and those matched with C-276 may be attributed to both the slight variation in chemical composition and as a result of the residual stress in the material due to the welding process - known to result in peak shift in XRD.

53. However, it is also evident from the obtained scan in this study that there are a number of peaks which have remained unindexed by the database; for example consider the data presented below (Table 2) comparing those peaks associated with C-276 and those which have been recorded.

\begin{tabular}{|c|c|c|c|c|c|}
\hline \multicolumn{2}{|c|}{ IN686CPT Scan } & \multicolumn{2}{c|}{ C-276 Matched Peaks } & \multicolumn{2}{c|}{ Unmatched Peaks } \\
\hline $\mathbf{2 \theta}$ & $\mathbf{d}(\mathbf{\AA})$ & $\mathbf{2 \theta}$ & $\mathbf{d}(\mathbf{\AA})$ & $\mathbf{2 \theta}$ & $\mathrm{d}(\mathbf{\AA})$ \\
\hline 29.91 & 2.98496 & 43.276 & 2.089 & 29.91 & 2.98496 \\
\hline 43.342 & 2.08599 & 50.375 & 1.81 & 44.519 & 2.0335 \\
\hline 44.519 & 2.0335 & 74.133 & 1.278 & 64.839 & 1.43681 \\
\hline 50.326 & 1.81164 & 90.039 & 1.089 & 82.117 & 1.17276 \\
\hline 64.839 & 1.43681 & & & & \\
\hline 74.094 & 1.27857 & & & & \\
\hline 82.117 & 1.17276 & & & & \\
\hline 89.743 & 1.09182 & & & & \\
\hline
\end{tabular}

Table 2: Comparison of $2 \theta$ and associated $d$ values for matched and unmatched peaks in XRD analysis

54. Based upon the data presented above, it is suggested that the unmatched peaks are those associated with the precipitation of an incoherent phase and thus not the peaks of the bulk metal matrix. 
Charpy Impact Toughness

55. There is significant variability in the energy absorbed by the specimens as shown in Table 3.

\begin{tabular}{|c|c|c|c|c|c|c|c|}
\hline \multirow{2}{*}{$\begin{array}{c}\text { Charpy } \\
\text { ID }\end{array}$} & \multirow{2}{*}{ Location } & \multirow[t]{2}{*}{ Filler Metal } & \multirow{2}{*}{$\begin{array}{l}\text { Test } \\
\text { Temp }\end{array}$} & \multicolumn{3}{|c|}{ Energy Absorbed } & \multirow{2}{*}{$\begin{array}{l}\text { Average } \\
\text { Energy } \\
\text { Absorbed }\end{array}$} \\
\hline & & & & $A$ & B & C & \\
\hline 554 & WM CL & IN625 & -40 & 148 & 154 & 142 & 148.00 \\
\hline 555 & WM CL & IN625 & -40 & 156 & 136 & 152 & 148.00 \\
\hline 556 & $45 \mathrm{FL}$ & IN625 & -40 & 122 & 131 & 222 & 158.33 \\
\hline 557 & $45 \mathrm{FL}$ & IN625 & -40 & 131 & 148 & 232 & 170.33 \\
\hline 558 & $90 \mathrm{FL}$ & IN686CPT & -40 & 217 & 166 & 232 & 205.00 \\
\hline 559 & $90 \mathrm{FL}$ & IN686CPT & -40 & 186 & 178 & 177 & 180.33 \\
\hline 691 & $90 \mathrm{FL}$ & IN686CPT & -40 & 86 & 210 & 72 & 122.67 \\
\hline 692 & $90 \mathrm{FL}$ & IN686CPT & -40 & 186 & 186 & 120 & 164.00 \\
\hline 703 & WM CL & IN686CPT & -40 & 128 & 132 & 130 & 130.00 \\
\hline 704 & WM CL & IN686CPT & -40 & 120 & 118 & 126 & 121.33 \\
\hline 571 & $90 \mathrm{FL}$ & IN625 & -40 & 181 & 246 & 234 & 220.33 \\
\hline 572 & $90 \mathrm{FL}$ & IN625 & -40 & 144 & 222 & 235 & 200.33 \\
\hline 573 & $90 \mathrm{FL}$ & IN625 & -40 & 222 & 168 & 150 & 180.00 \\
\hline 574 & $90 \mathrm{FL}$ & IN625 & -40 & 224 & 126 & 200 & 183.33 \\
\hline 575 & $45 \mathrm{FL}$ & IN686CPT & -40 & 90 & 61 & 170 & 107.00 \\
\hline 576 & $45 \mathrm{FL}$ & IN686CPT & -40 & 222 & 100 & 182 & 168.00 \\
\hline
\end{tabular}

Table 3: Charpy V Notch Impact Testing Results

56. For example, it is observed that within set 691 , with 3 samples of IN686CPT all notched on $90^{\circ} \mathrm{FL}$ to a high degree of accuracy, the maximum recorded energy was $210 \mathrm{~J}$ while the minimum was $72 \mathrm{~J}$. The fracture surfaces of these two specimens exhibited significant differences. In the specimen labelled as 691B the failure has occurred predominantly in the parent material and the fracture was ductile, with a considerable 'tearing' effect. However, in the specimen labelled 691C the fracture has occurred through the fusion line and a brittle fracture surface was observed. (Figure 15). In order to demonstrate the variation in fracture surfaces to a greater extent, SEM fracture micrographs were taken and may be observed in Figures 16A and $16 \mathrm{~B}$ for $691 \mathrm{~B}$ and $691 \mathrm{C}$ respectively. Upon further investigation, the disparity in fracture modes was apparent; 691B exhibited a ductile fracture as evidenced by the elongated dimples on the surface. However, 691C demonstrated an obvious brittle fracture where cleavage may be observed on the planar, crystallographic fracture surface.

57. Higher values of energy absorbed were obtained in all IN625 specimens (Figure 17), demonstrating IN625 has superior impact toughness to IN686CPT. It should also be noted that the results have been averaged for each notch location in order to observe general trends 
58. Furthermore, the particularly low values of impact toughness observed $(<100 \mathrm{~J})$ were only seen in the specimens welded using IN686CPT as the filler metal. The lowest value obtained using IN625 was 122J (45 $\left.{ }^{\circ} \mathrm{FL}\right)$ and when using IN686CPT was $61 \mathrm{~J}$ $\left(45^{\circ} \mathrm{FL}\right)$.

59. Based upon present findings it is suggested that, in the specimens which have the lowest values of impact toughness, fracture has occurred through the network of brittle precipitates as previously speculated. However, it is suggested that in the specimens which have high values of energy absorbed, the crack propagation has not 'found' this brittle network and thus has favoured the parent material.

60. This hypothesis of fracture occurring through the brittle network of precipitates was further evaluated by imaging the fractured surface of the specimen which gave the lowest absorbed energy in the etched condition. It should be noted that since the specimen with the lowest absorbed energy was one which was notched on the $45^{\circ} \mathrm{FL}$, only the IN686CPT material was imaged. The results are presented in Figure 18. When using backscattered electron mode (BSE), it was observed that there was a high volume fraction of precipitate in the dendrite arms along which the fracture had propagated. It is reasonable to suggest that what is observed here are the precipitates previously noted under SEM and LOM examination, because they are only apparent in the etched condition and appear bright in BSE mode. Since elements of a greater atomic mass appear lighter when imaged in BSE, it is likely that these regions are enriched with molybdenum and tungsten and thus consistent with being eutectic precipitates formed as a result of elemental segregation. It is therefore suggested that the precipitates shown are brittle in nature and have facilitated the fracture by providing a path of least resistance. 


\section{Conclusions}

61. Iron dilution from the parent material occurs throughout the weld with the highest $23.4 \%$ dilution being recorded on the weldment side with the larger surface area $\left(45^{\circ}\right.$ side) and thus higher heat input compared to $12.8 \%$ and lower heat input on the $90^{\circ}$ side. Furthermore, significant, although reduced, iron dilution has occurred in the centre of the weldments with values of approximately $5 \%$ recorded.

62. The data presented suggest that both the segregation potential of tungsten and its enrichment of the phase precipitated in IN686CPT is a function of iron dilution in the weld metal. It has been established that that the $k$ value associated with tungsten varies across the weld with a value of 0.96 in the centre line region and a value of 0.86 at the $45^{\circ} \mathrm{FL}$. It has also been shown that the presence of tungsten in the precipitated phase appears to have a notable effect on its morphology and causes it to become continuous. EBSD and XRD techniques have also been utilised in order to confirm the presence of an incoherent phase within the bulk metal matrix.

63. Charpy impact testing has demonstrated that the impact toughness of IN625 is superior to IN686CPT in all instances and the presence of the observed interdendritic precipitates is proposed as the reason for this reduction in impact toughness. Furthermore, the low impact toughness values recorded in welds made using IN686CPT have been postulated to be the result of the fracture occurring through the network of brittle phase precipitation. 


\section{Acknowledgements}

This work was supported by the Pipeline Production Group division of Subsea 7. The author would also like to gratefully acknowledge the support and expertise of the AMRL department of the University of Strathclyde.

\section{References}

1 F. J. Xu, Y. H. Lv, B. S. Xu, Y. X. Liu, F. Y. Shu and P. He: Materials and Design, 2013, vol. 45, pp. 446-455.

2 H. R. Zareie Rajani, S. A. A. Akbari Mousavi and F. Madani Sani: Materials and Design, 2013, vol. 43, pp. 467-474.

$3 \quad$ M.C. Maguire, J.R. Michael: Superalloys 718, 625, 706 and Various Derivatives, E.A. Loria (Ed.), The Minerals, Metals and Materials Society, Pennsylvania, 1994, pp. 881-892.

4 J. N. DuPont, S. W. Banovic and A. R. Marder: Welding Journal, 2003, vol. 82, pp. 125S-135S.

5 S. W. Banovic, J. N. DuPont and A. R. Marder: Science and Technology of Welding and Joining, 2002, vol. 7, pp. 374-383.

$6 \quad$ M. Cieslak, T. Headley and R. Frank: Welding Journal, 1989, vol. 68, pp. 473482.

$7 \quad$ M. Cieslak, Welding journal: 1991, vol. 70, pp. 49s-56s.

8 J. DuPont: Metallurgical and Materials Transactions A, 1996, vol. 27, pp. 3612-3620.

$9 \quad$ S. Floreen, G. E. Fuchs and W. J. Yang: Superalloys 718, 625, 706 and Various Derivatives, E. A. Loria (Ed.), The Minerals, Metals and Materials Society, Pennsylvania, 1994, pp. 13-37.

10 C. C. Silva, H. C. d. Miranda, M. F. Motta, J. P. Farias, C. R. M. Afonso and A. J. Ramirez: Journal of Materials Research and Technology, 2013, vol. 2, pp. 228-237.

11 J. N. DuPont, J. C. Lippold and S. D. Kiser: Welding Metallurgy and Weldability of Nickel-Base Alloys, John Wiley \& Sons, Hoboken NJ USA, 2009, pp. 47-157.

12 T. S. Edgecumbe, R. B. Rebak and R. R. Seeley: The Minerals-MetalsMaterials Society Conference, Lawrence Livermore National Laboratory, St. Louis MO USA, 2000.

13 S.-L. Jeng and Y.-H. Chang: Materials Science and Engineering A, 2012, vol. 555, pp. 1-12.

14 J. S. Ogborn, D. L. Olson and M. J. Cieslak: Materials Science and Engineering A, 1995, vol. 203, pp. 134-139.

15 M. J. Perricone, J. N. DuPont and M. J. Cieslak: Metallurgical and Materials Transactions A, 2003, vol. 34, pp. 1127-1132.

16 D. Stefanescu: Science and Engineering of Casting Solidification, Second Edition, Springer US, 233 Spring Street, NY 10013, USA, 2009, pp. 135-139.

17 S.V. Nagender Naidum, A.M. Sriramamurthy, P. Rama Rao: Phase Diagrams of Binary Iron Alloys, in: H. Baker (Ed.) Alloy Phase Diagrams, vol 3, pp. 873874, ASM International, Materials Park OH, 1992.

18 S. K. Rai, A. Kumar, V. Shankar, T. Jayakumar, K. Bhanu Sankara Rao and B. Raj: Scripta Materialia, 2004, vol. 51, pp. 59-63. 
19 M. Donachie and S. Donachie: Grain-Boundary Carbides in Nickel Base Superalloys, in: M. Donachie (Ed.) Superalloys: a Technical Guide, ASM International, Materials Park OH, pp. 218-221, 2002.

20 A. Yeh and S. Tin: Metallurgical and Materials Transactions A, 2006, vol. 37, pp. 2621-2631.

21 F. d. S. Borchardt: Characterization of the proeutectoid cementite networks observed in the SAE 1092 wire rod steel grade, 2004, University of Pittsburgh, Pittsburgh, pp. 54-55

22 M. Ahmad, J. I. Akhter, M. Iqbal, M. Akhtar, E. Ahmed, M. A. Shaikh and K. Saeed: Journal of Nuclear Materials, 2005, vol. 336, pp. 120-124. 


\section{List of Figures}

- Figure 1 - Macro specimens illustrating weld set up where fusion lines are at $90^{\circ}$ and $45^{\circ}$ to the horizontal. Specimens were etched using $5 \%$ electrolytic Nital.

- Figure 2 - Charpy notch locations showing notch located at $90^{\circ} \mathrm{FL}$ (top); WMCL (middle); and $45^{\circ} \mathrm{FL}$ (bottom)

- Figure 3A - IN686CPT micrograph showing $45^{\circ} \mathrm{FL}$, two precipitate morphologies are observed: continuous type morphology, and a finer precipitation both formed in interdendritic regions.

- Figure 3B - IN686CPT micrograph showing WMCL; dendrite coring is less apparent and the precipitate morphology is globular in nature.

- Figure 3C - IN686CPT micrograph showing 90 FL; precipitate morphology is predominantly globular with a smaller volume fraction of continuous morphologies also evident.

- Figure 4A - IN625 micrograph showing $45^{\circ} \mathrm{FL}$; apparent volume fraction of precipitate is lower and the morphology is predominantly globular in nature.

- Figure 4B - IN625 micrograph showing WMCL; precipitation has occurred in interdendritic regions, the morphology is consistent and globular in nature

- Figure 4C - IN625 micrograph showing $90^{\circ} \mathrm{FL}$; precipitate morphology is observed to be globular. The region on the right hand side of the micrograph is the fusion line between parent material and weld metal.

- Figure 5 - Iron dilution results as obtained by EDS, showing significantly higher percentage dilution on the $45^{\circ} \mathrm{FL}$ side of the weld than on the $90^{\circ} \mathrm{FL}$ side. Note that although dilution levels are lower in the centre of the weld, dilution has still occurred to some extent.

- Figure 6A - IN625 typical precipitate morphology imaged using SEM in secondary electron (SE) mode. Morphology was observed to be consistently globular across the weld.

- Figure 6B - IN686CPT precipitate morphology imaged using SEM in secondary electron (SE) mode. Both continuous and globular type morphologies were observed in IN686CPT weld metal, the dominant morphology appeared to be related to location of analysis.

- Figure 7A - EDS analysis of IN686CPT precipitate located in the region of the $45^{\circ} \mathrm{FL}$, demonstrating the enrichment of $\mathrm{W}$ and $\mathrm{Mo}$ and depletion of $\mathrm{Fe}$ and $\mathrm{Ni}$ relative to the bulk matrix.

- Figure 7B - Relative enrichment and depletion of key alloying additions in IN686CPT precipitate. Enrichment was determined by dividing the precipitate composition by that of the pre weld composition hence a dimensionless unit of $y$-axis. 
- Figure 8 - Results of EDS line scans conducted across dendrite cores and interdendritic regions in each of the 3 areas of interest. The results demonstrate the most significant variability of tungsten content at the $45^{\circ} \mathrm{FL}$ location and hence this is associated with the lowest value of $k$. Note that the variability is dependent upon analysis location and therefore substantiating the suggestion that tungsten segregation is a function of iron content within the alloy.

- Figure 9 - Relative enrichment to pre-weld composition of tungsten in IN686CPT weld metal. Plots represent line scans across 3 precipitates of similar morphologies from each of the 3 areas of interest. It is apparent that the enrichment at the $45^{\circ} \mathrm{FL}$ is the most significant, where iron dilution was also the largest, thus further substantiating the relationship between iron dilution and tungsten segregation.

- Figure 10 - Relative enrichment of globular precipitate located in the WMCL cap region of the weld showing a significant enrichment of molybdenum and a greatly reduced tungsten enrichment

- Figure 11 - Relative enrichment to pre-weld composition of molybdenum in IN686CPT weld metal. Plots represent line scans across 3 precipitates of similar morphologies from each of the 3 areas of interest.

- Figure 12 - EBSD grain mapping in $45^{\circ} \mathrm{FL}$ region of IN686CPT weld metal. Note the large grains characteristic of the material and the smaller regions of high crystallographic misorientation, likely to be the precipitates previously observed.

- Figure 13 - EBSD grain mapping as in Fig. 12 at higher magnification. Note the purple 'island' within the dark blue grain which is likely to be a precipitate as previously observed.

- Figure 14A - XRD map obtained for IN686CPT sample, the red peaks are those associated with the IN686CPT weld metal scan and the blue peaks are those matched as being associated with $\mathrm{C}-276$ - which is of a very similar composition to that of IN686CPT.

- Figure $14 \mathrm{~B}$ - Higher magnification image of the XRD peaks as shown in Fig. $14 A$.

- Figure 15 - Charpy fracture surfaces demonstrating variability obtained in fracture modes when specimens are notched in the same location. Specimen 691B (right) absorbed 210J whereas specimen 691C (left) absorbed 72J.

- Figure 16A - SEM fractograph of 691B demonstrating ductile failure with elongated dimples evident on the fracture surface.

- Figure 16B - SEM fractograph of 691C demonstrating brittle failure where cleavage may be observed on the planar fracture surface 
- Figure 17 - Charpy impact results demonstrating superior toughness of IN625 in all notch locations. The results have been averaged for each notch location such that general trends may be observed.

- Figure 18 - SEM fractograph of specimen 575B using backscattered electron (BSE) mode following electrolytic etch in oxalic acid. Note the bright particles on the fracture surface likely to be the precipitates observed previously. 


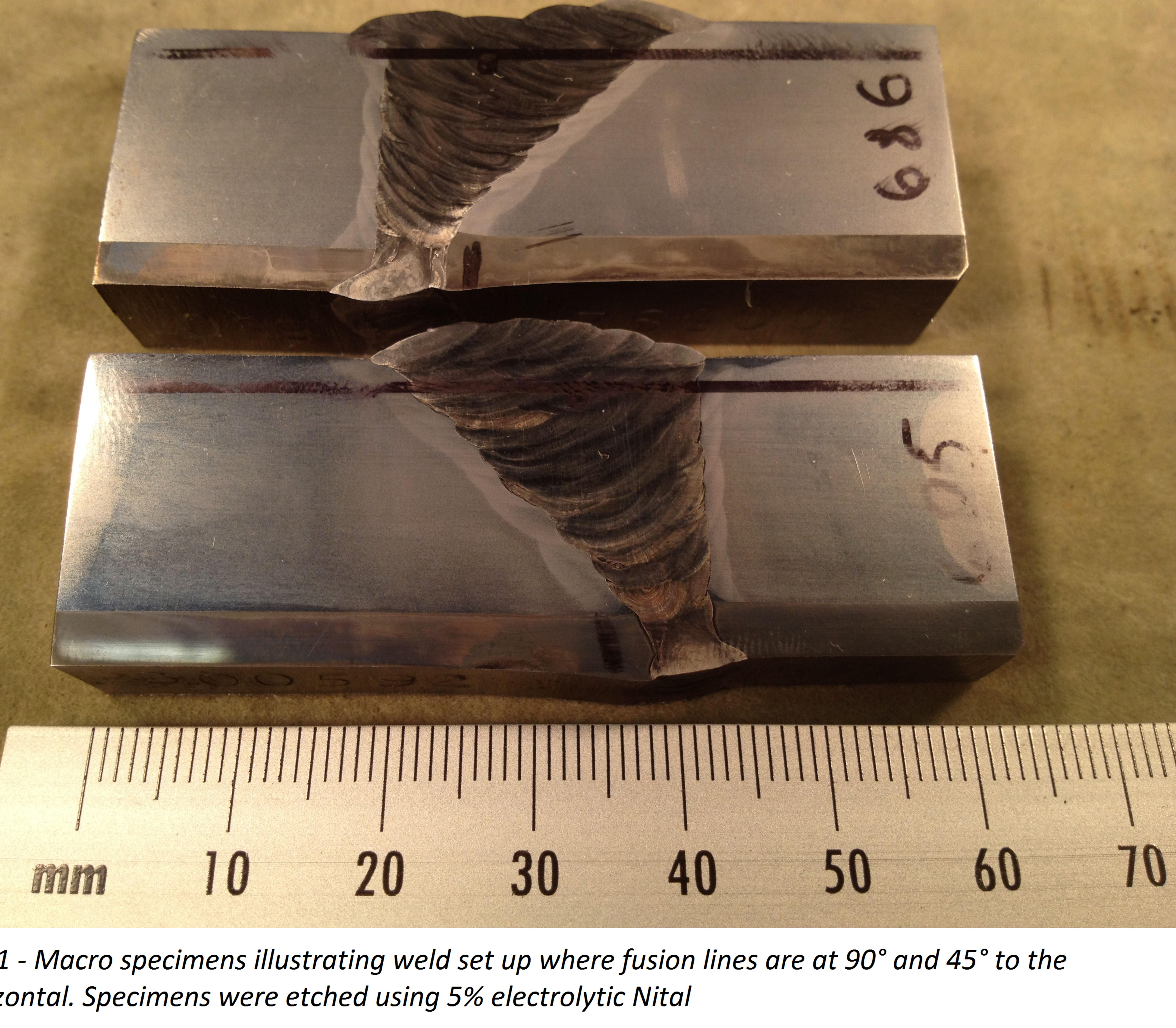




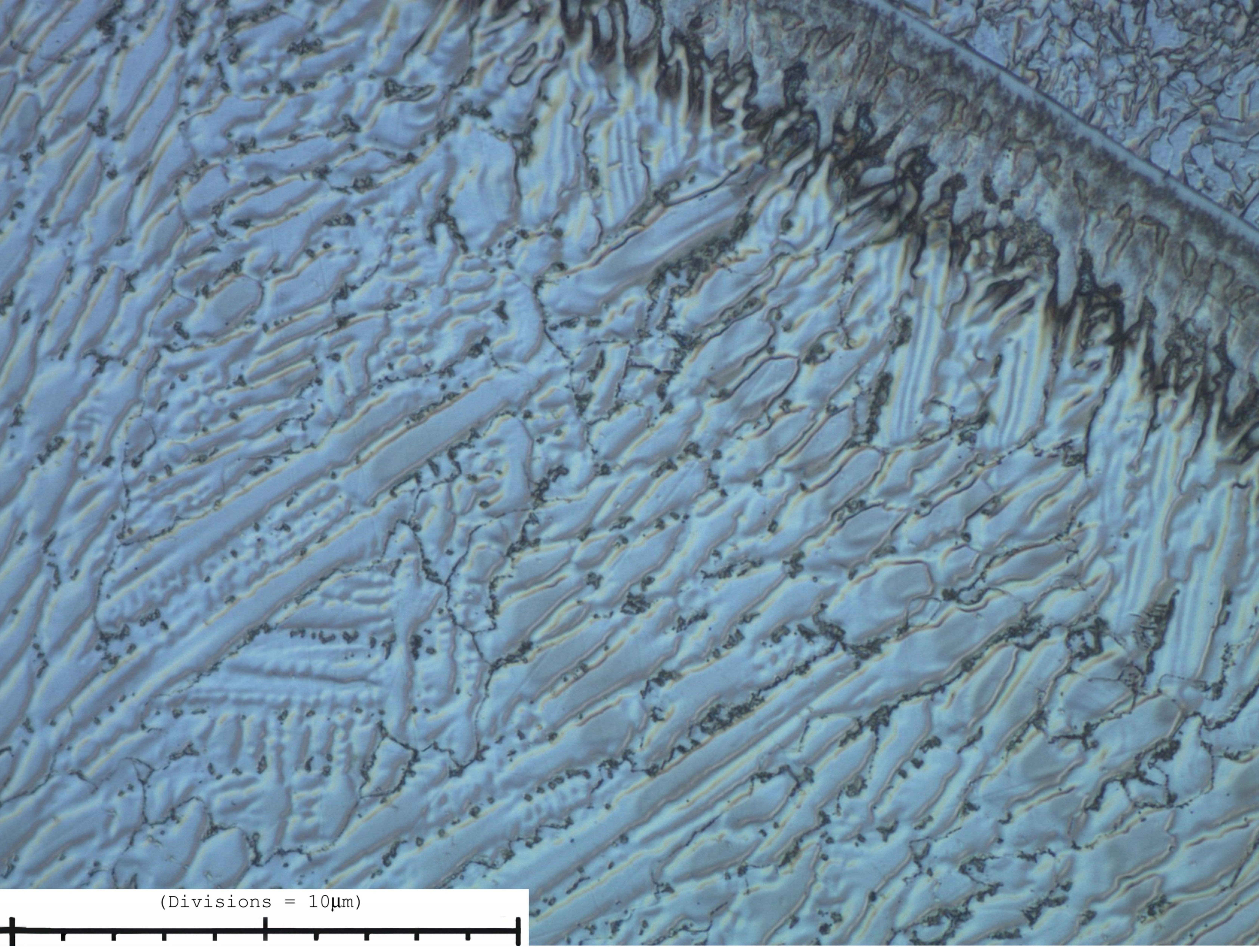

Fig. 3A - IN686CPT micrograph showing $45^{\circ} \mathrm{FL}$, two precipitate morphologies are observed: continuous type morphology, and a finer precipitation both formed in interdendritic regions 


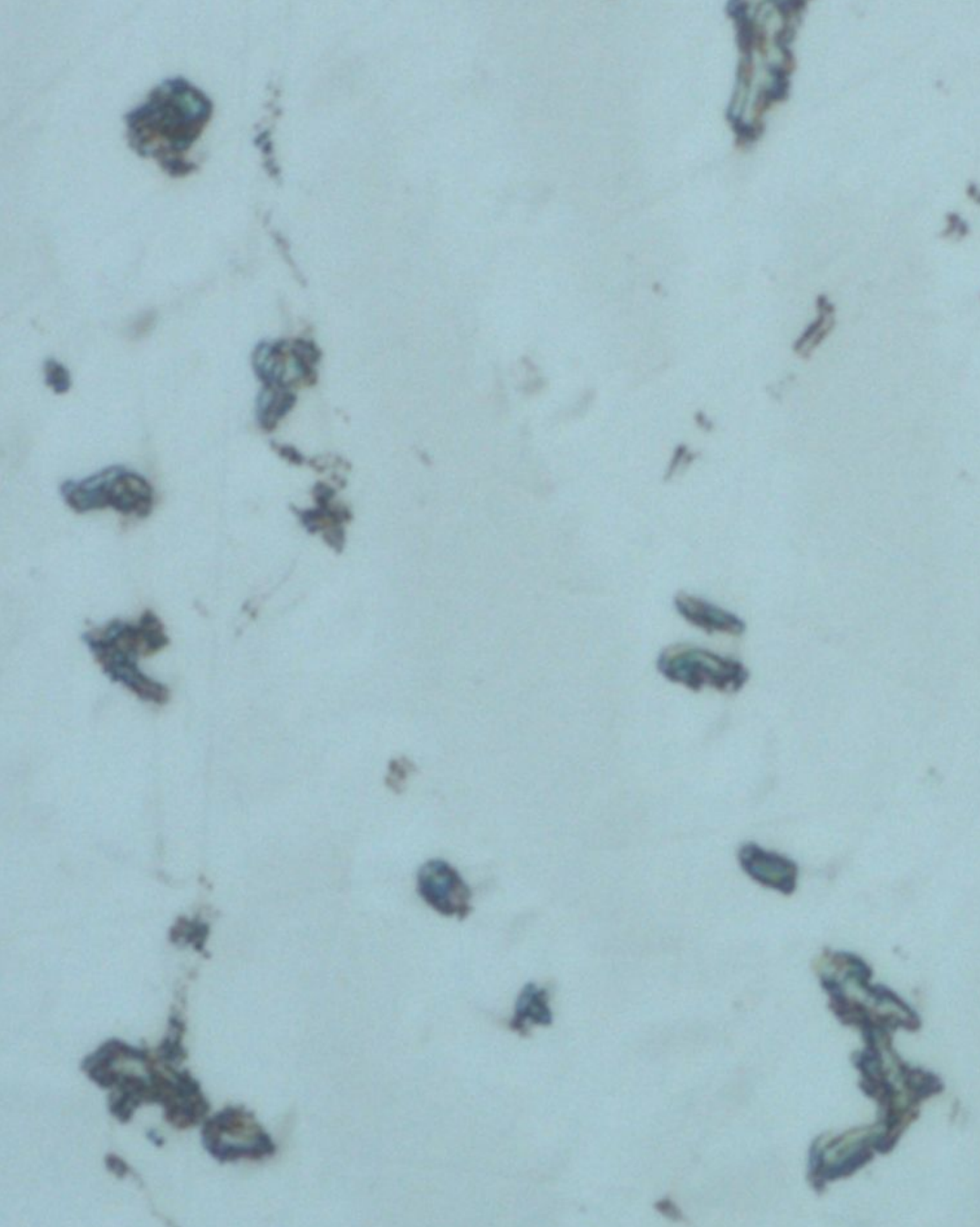

F

Fig. 3B - IN686CPT micrograph showing WMCL; dendrite coring is less apparent and the precipitate morphology is globular in nature 



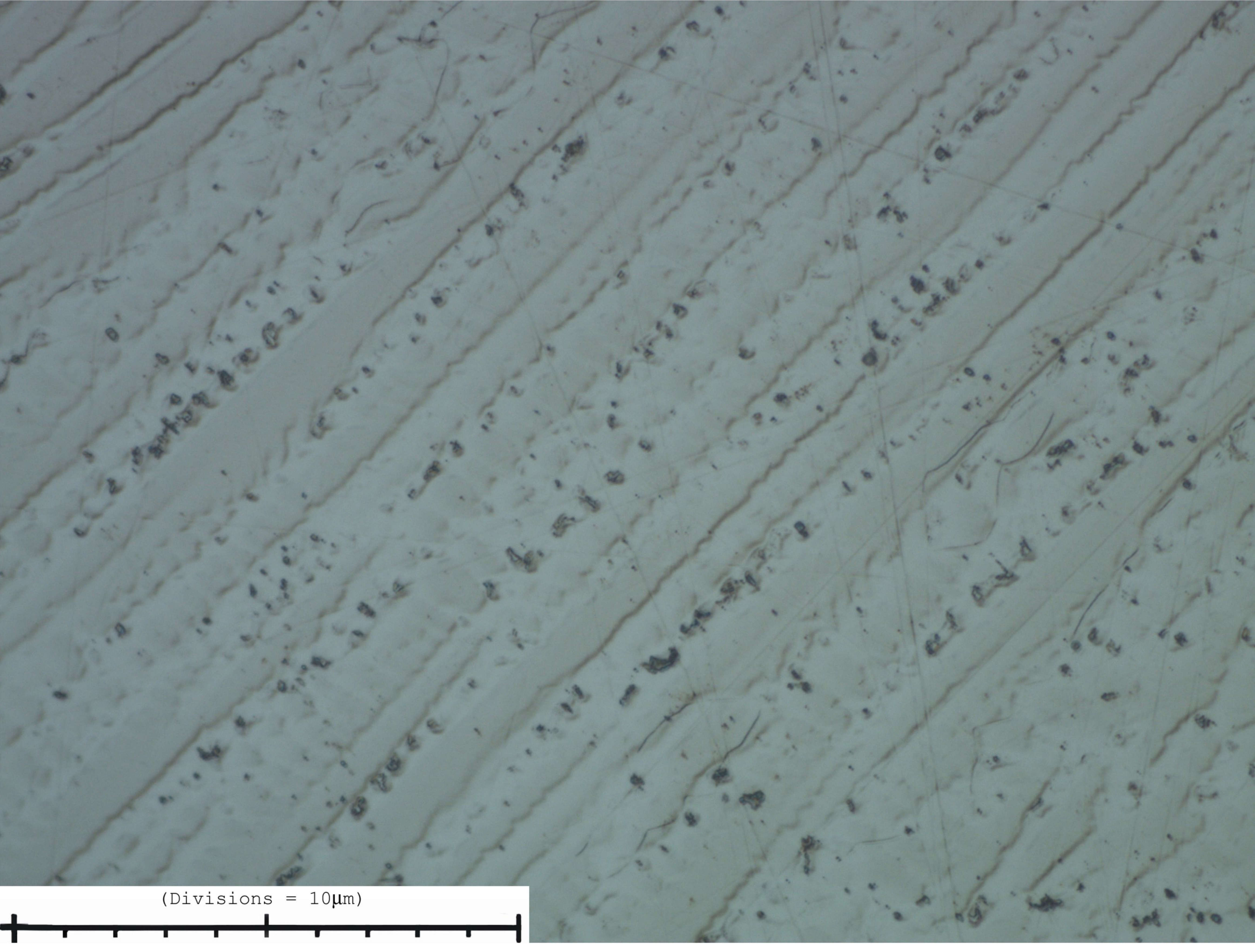

Fig. 4B - IN625 micrograph showing WMCL; precipitation has occured in interdendritic regions, the morphology is consistent and globular in nature 
Fig. 4C - IN625 micrograph showing $90^{\circ} \mathrm{FL}$; precipitate morphology is observed to be globular. The region on the right hand side of the micrograph is the fusion line between parent material and weld metal. 


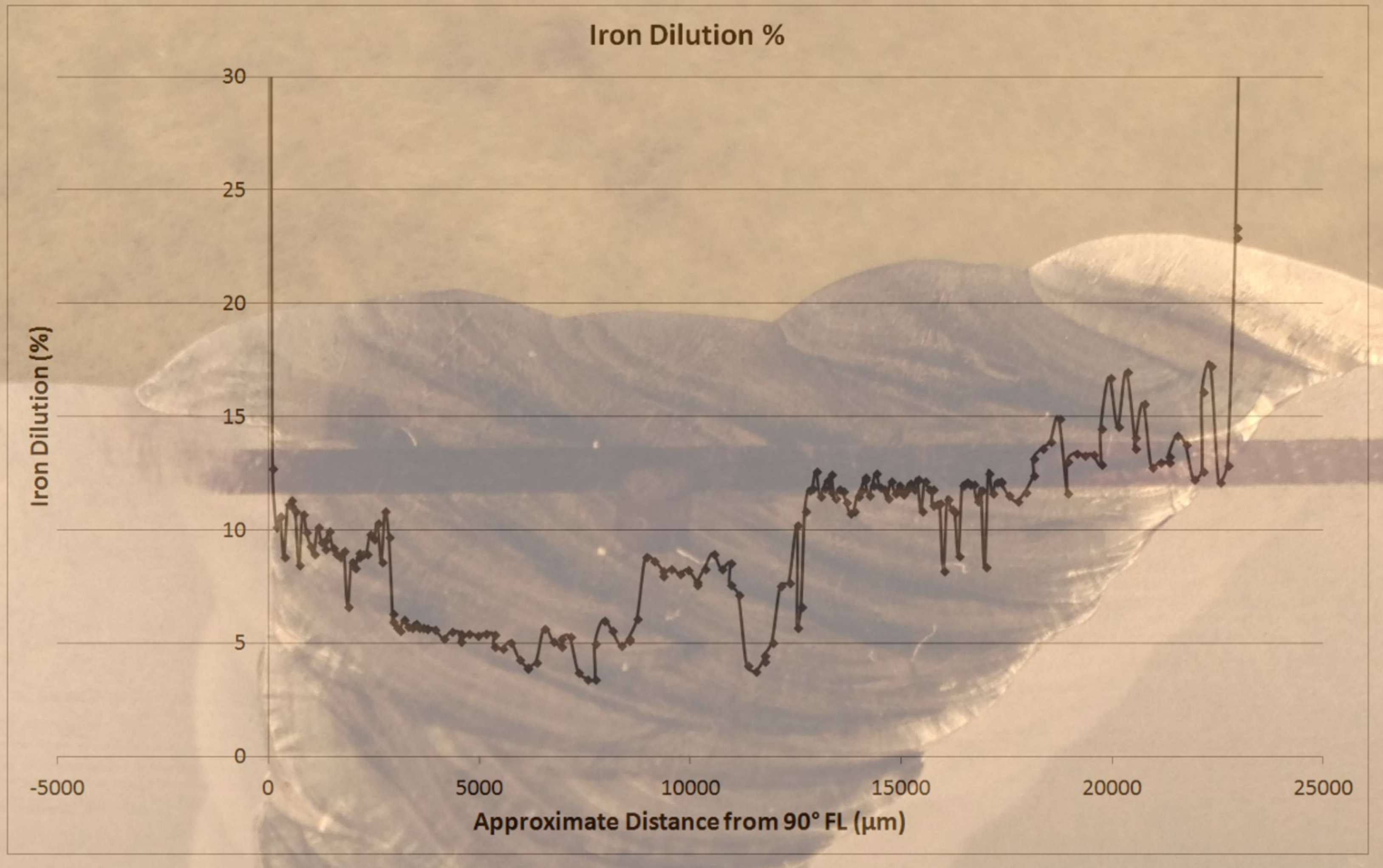

Fig. 5 - Iron dilution results as obtained by EDS, showing significantly higher percentage dilution on the $45^{\circ} \mathrm{FL}$ side of the weld than on the $90^{\circ} \mathrm{FL}$ side. Note that although dilution levels are lower in the centre of the weld, dilution has still occurred to some extent. 
Fig. 6A - IN625 typical precipitate morphology imaged using SEM in secondary electron (SE) mode. Morphology was observed to be consistently globular across the weld. 

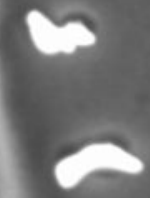

S3700 20.0kV 10.0mm $\times 4.00 \mathrm{k}$ SE $2 / 21 / 2013$

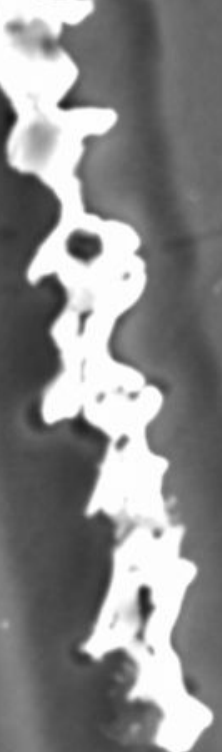

Fig. 6B - IN686CPT precipitate morphology imaged using SEM in secondary electron (SE) mode. Both continuous and globular type morphologies were observed in IN686CPT weld metal, the dominant morphology appeared to be related to location of analysis 


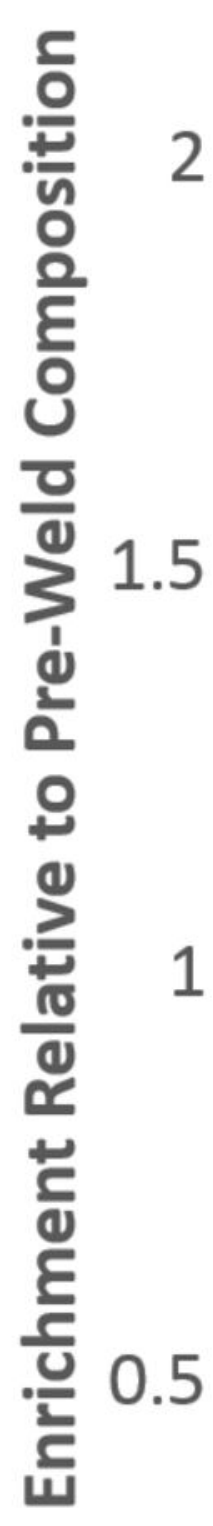

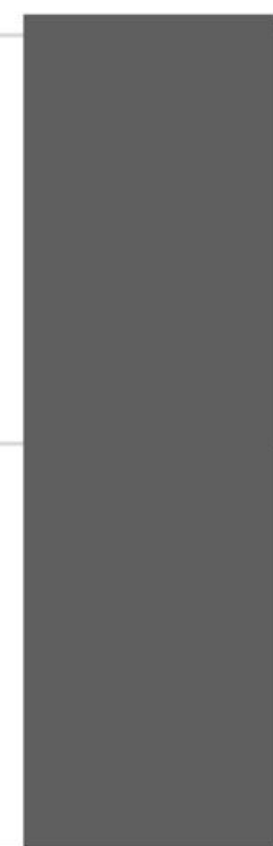

Mo

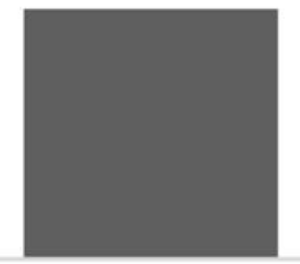

W

0

Fig. 7B - Relative enrichment and depletion of key alloying additions in IN686CPT precipitate. Enrichment was determined by dividing the precipitate composition by that of the pre weld composition hence a dimensionless unit of $y$-axis. 


$$
\text { M D }
$$




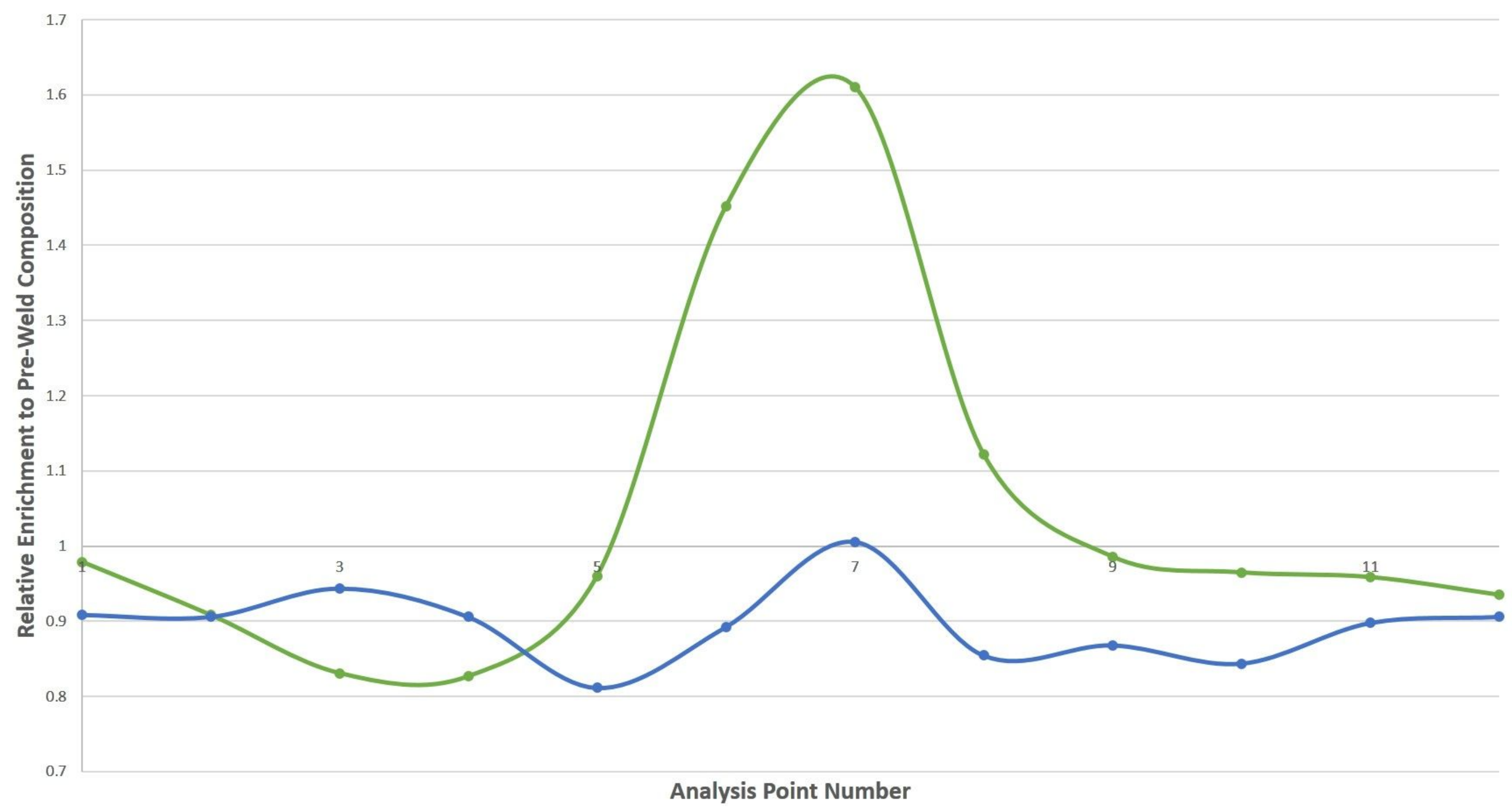

Fig. 10 - Relative enrichment of globular precipitate located in the WMCL cap region of the weld showing a significant enrichment of molybdenum and a greatly reduced tungsten enrichment. 


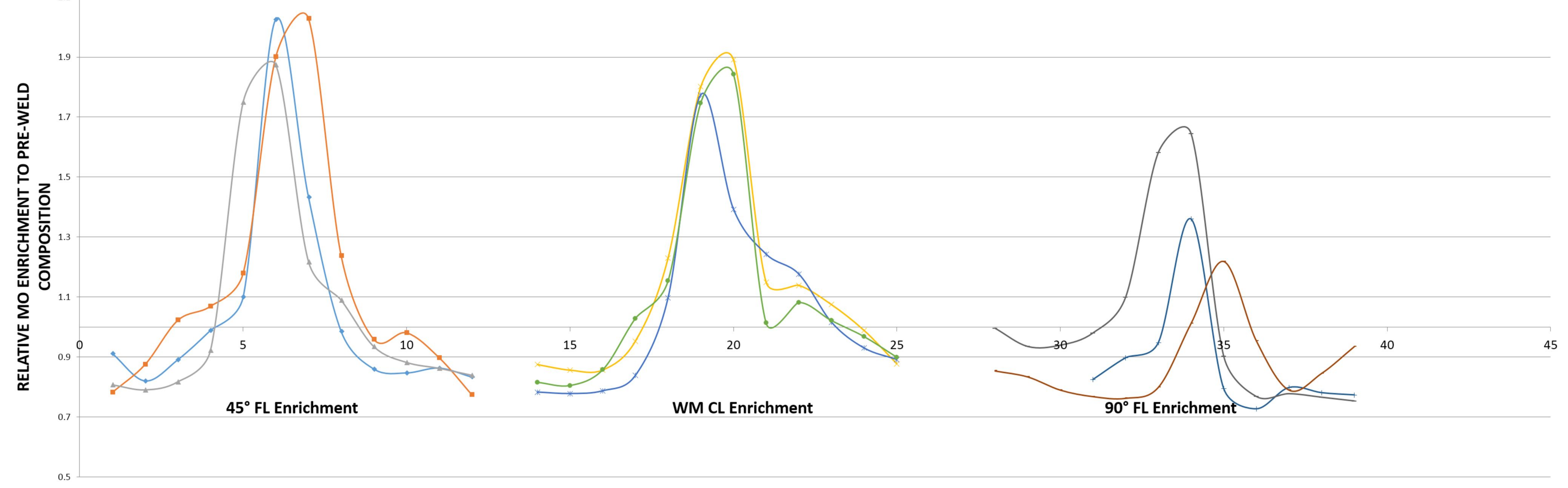

Fig. 11 - Relative enrichment to pre-weld composition of molybdenum in IN686CPT weld metal. Plots represent line scans across 3 precipitates of similar morphologies from each of the 3 areas of interest. 


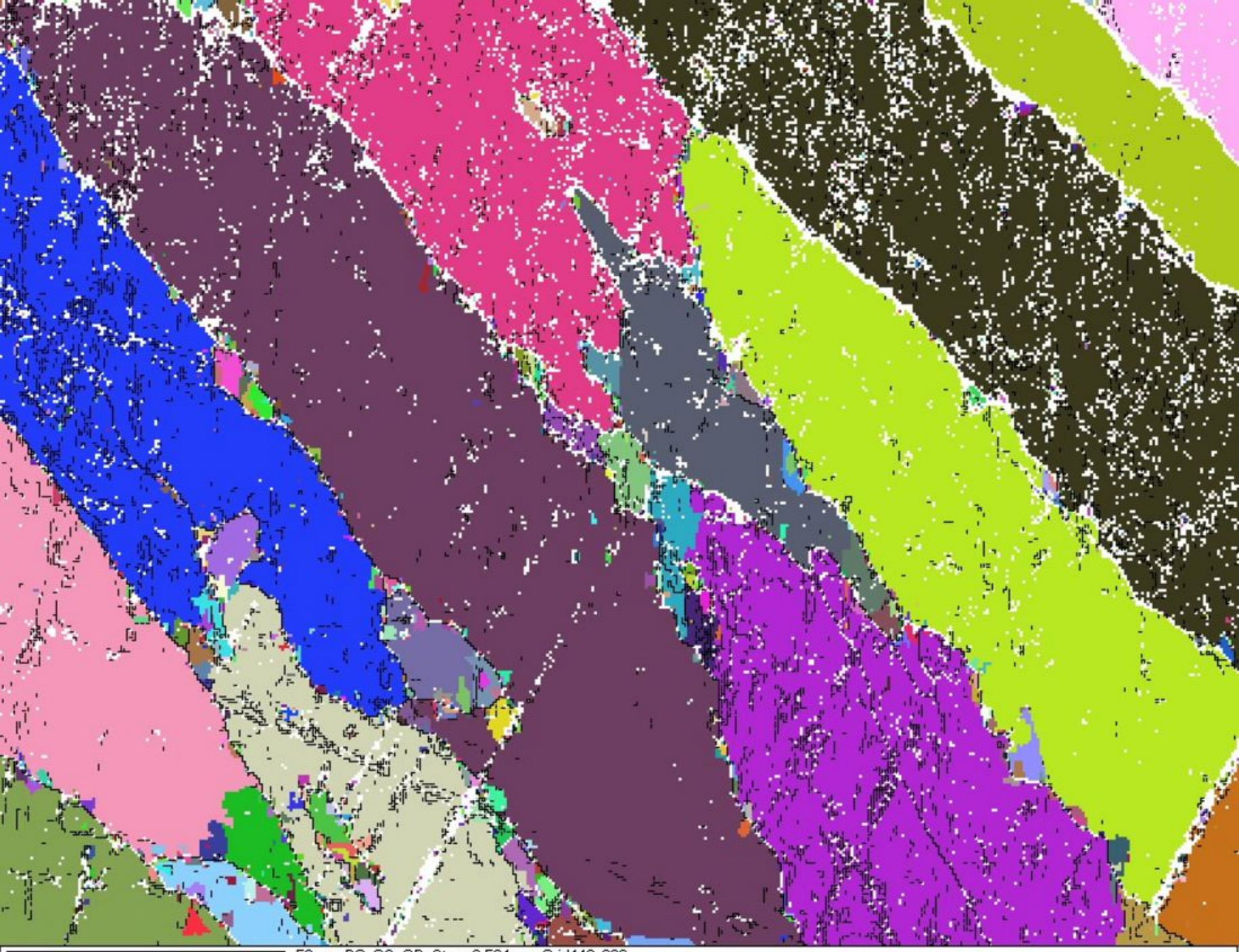

$=50 \mu \mathrm{m} ; \mathrm{BC}+\mathrm{GS}+\mathrm{GB} ;$ Step $=0.504 \mu \mathrm{m} ;$ Grid440*336

Fig. 12 - EBSD grain mapping in $45^{\circ} \mathrm{FL}$ region of IN686CPT weld metal. Note the large grains characteristic of the material and the smaller regions of high crystallographic misorientation, likely to be the precipitates previously observed. 


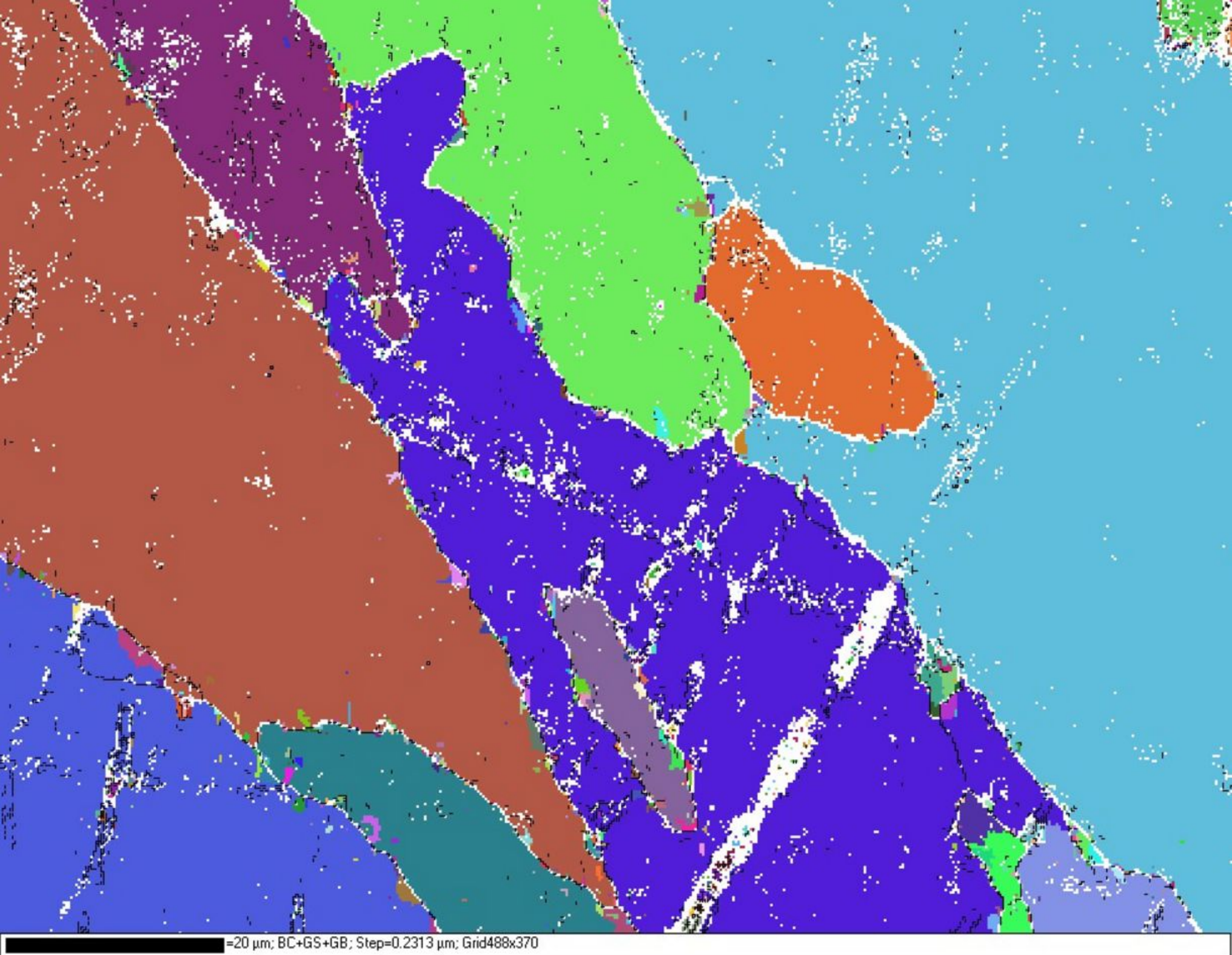

Fig. 13 - EBSD grain mapping as in Fig. 12 at higher magnification. Note the purple 'island' within the dark blue grain which is likely to be a precipitate as previously observed 


\section{Commander Sample ID (Coupled TwoTheta/Theta)}

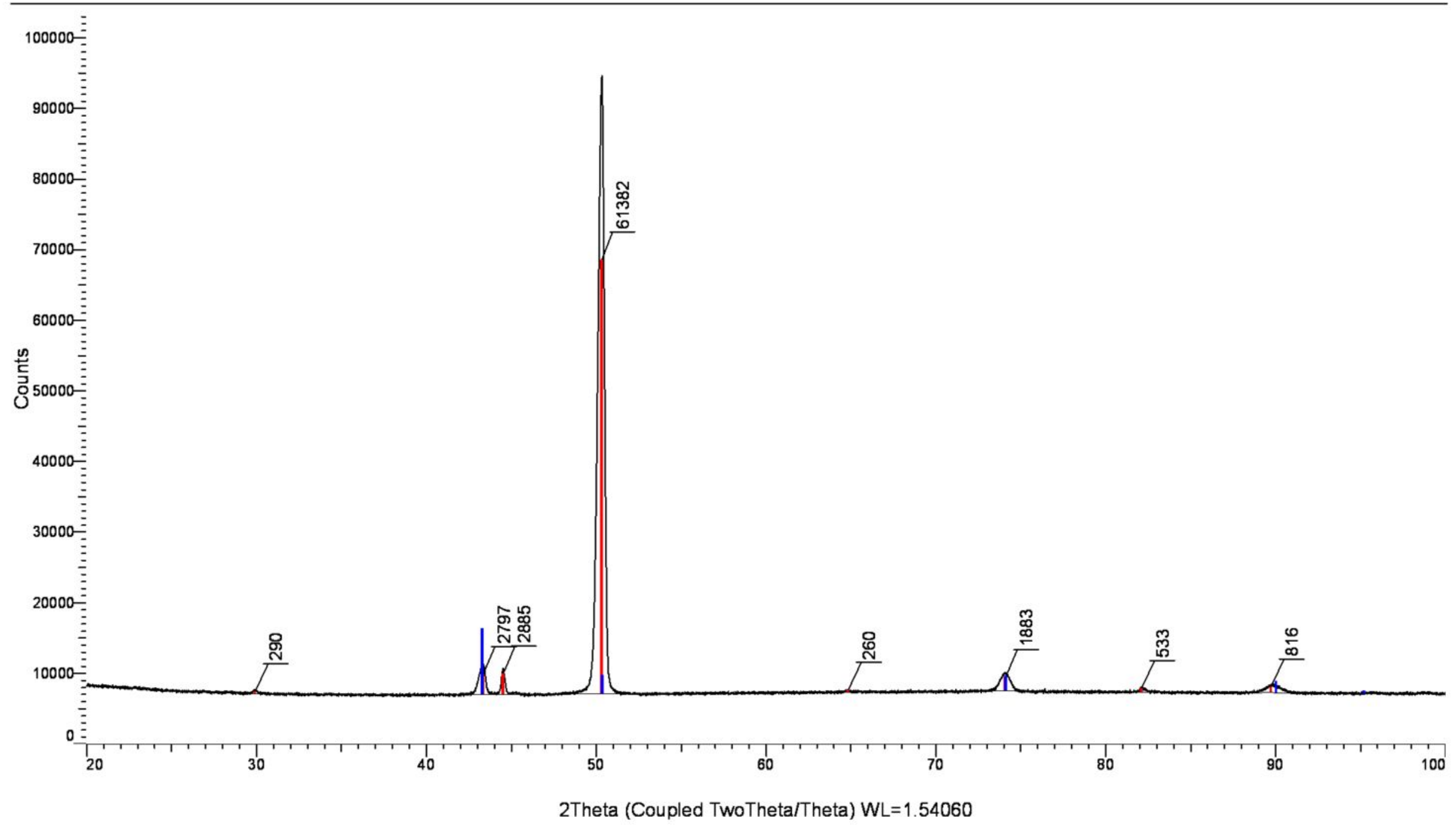

Fig. 14A - XRD map obtained for IN686CPT sample, the red peaks are those associated with the IN686CPT weld metal scan and the blue peaks are those matched as being assoicated with C-276 - which is of a very similar composition to that of IN686CPT 


\section{Commander Sample ID (Coupled TwoTheta/Theta)}

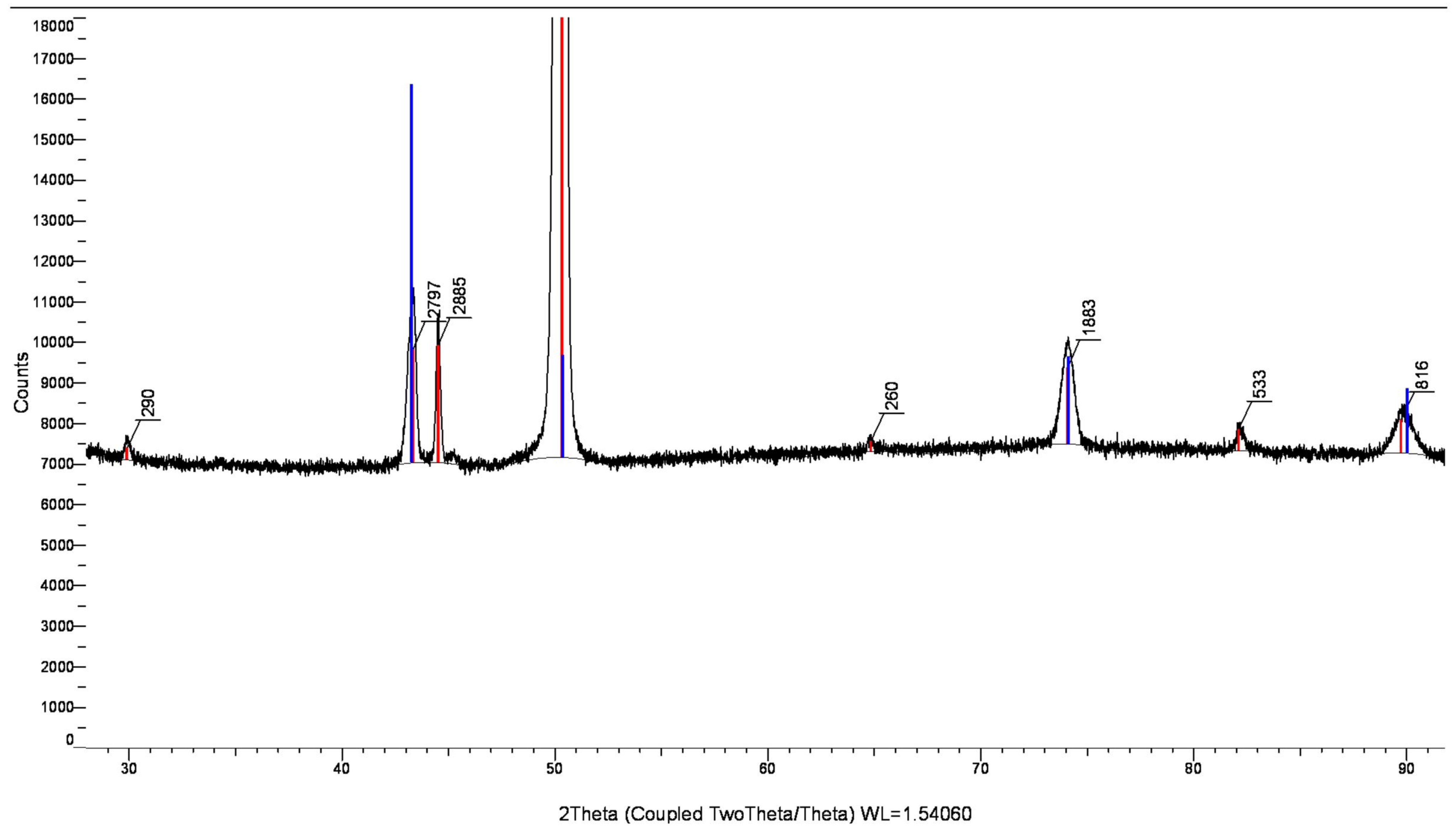

Fig. 14B - Higher magnification image of the XRD peaks as shown in Fig. 14A. 

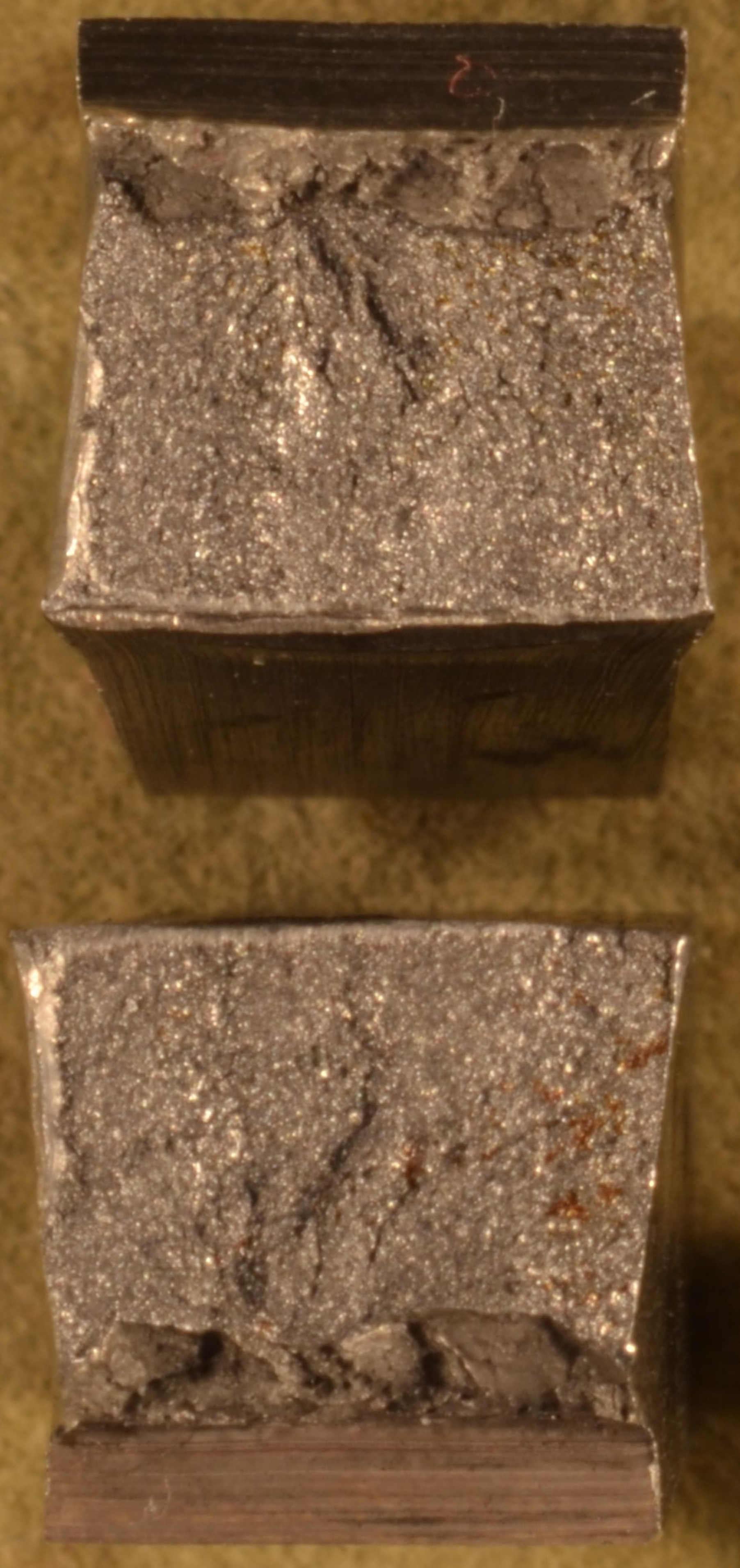

Fig 15 - Charpy fracture surfaces demonstrating variability obtained in fracture modes when specimens are notched in the same location. Specimen 691B (right) absorbed 210J whereas specimen $691 \mathrm{C}$ (left) absorbed 72J. 


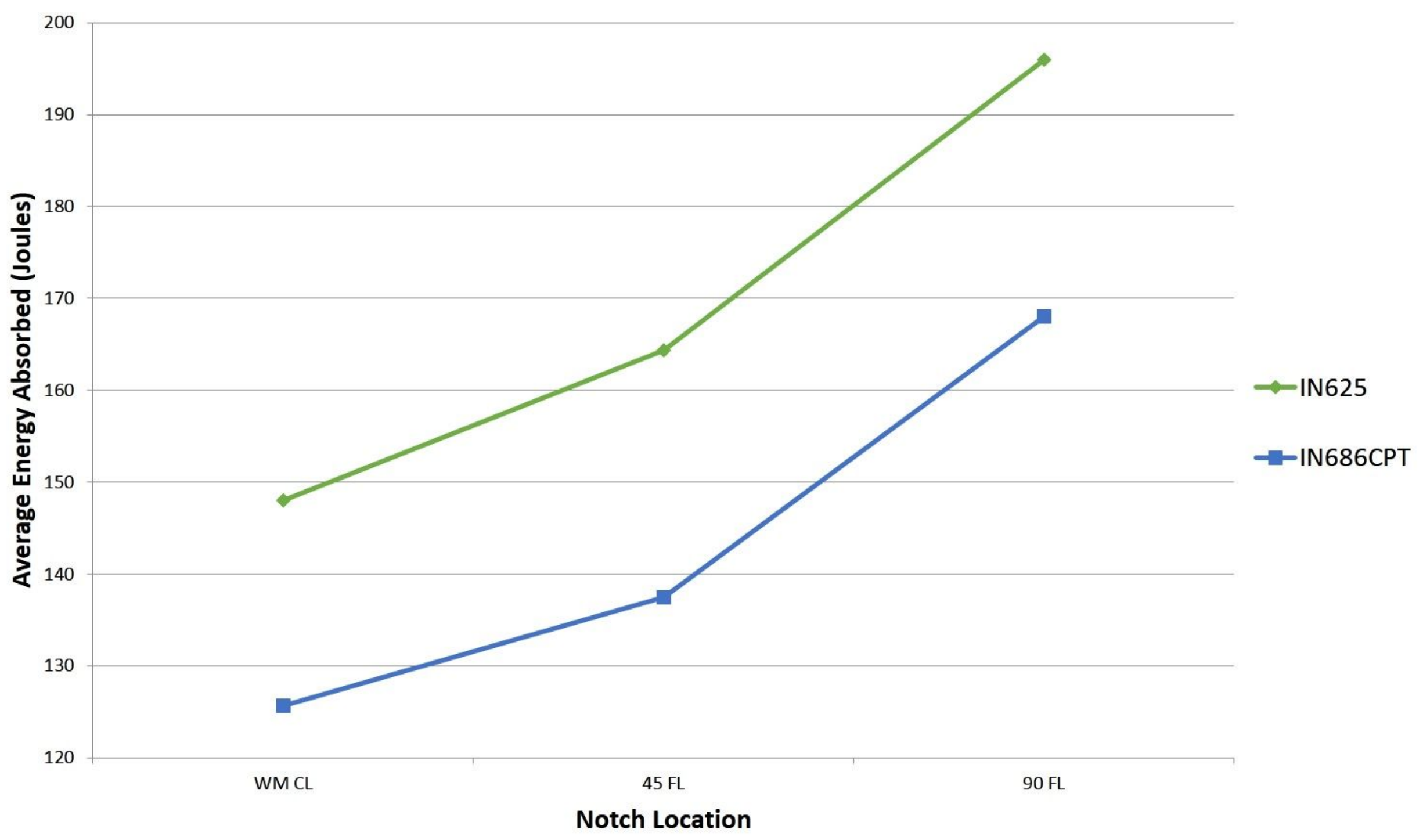

Fig. 17 - Charpy impact results demonstrating superior toughness of IN625 in all notch locations. The results have been averaged for each notch location such that general trends may be observed 


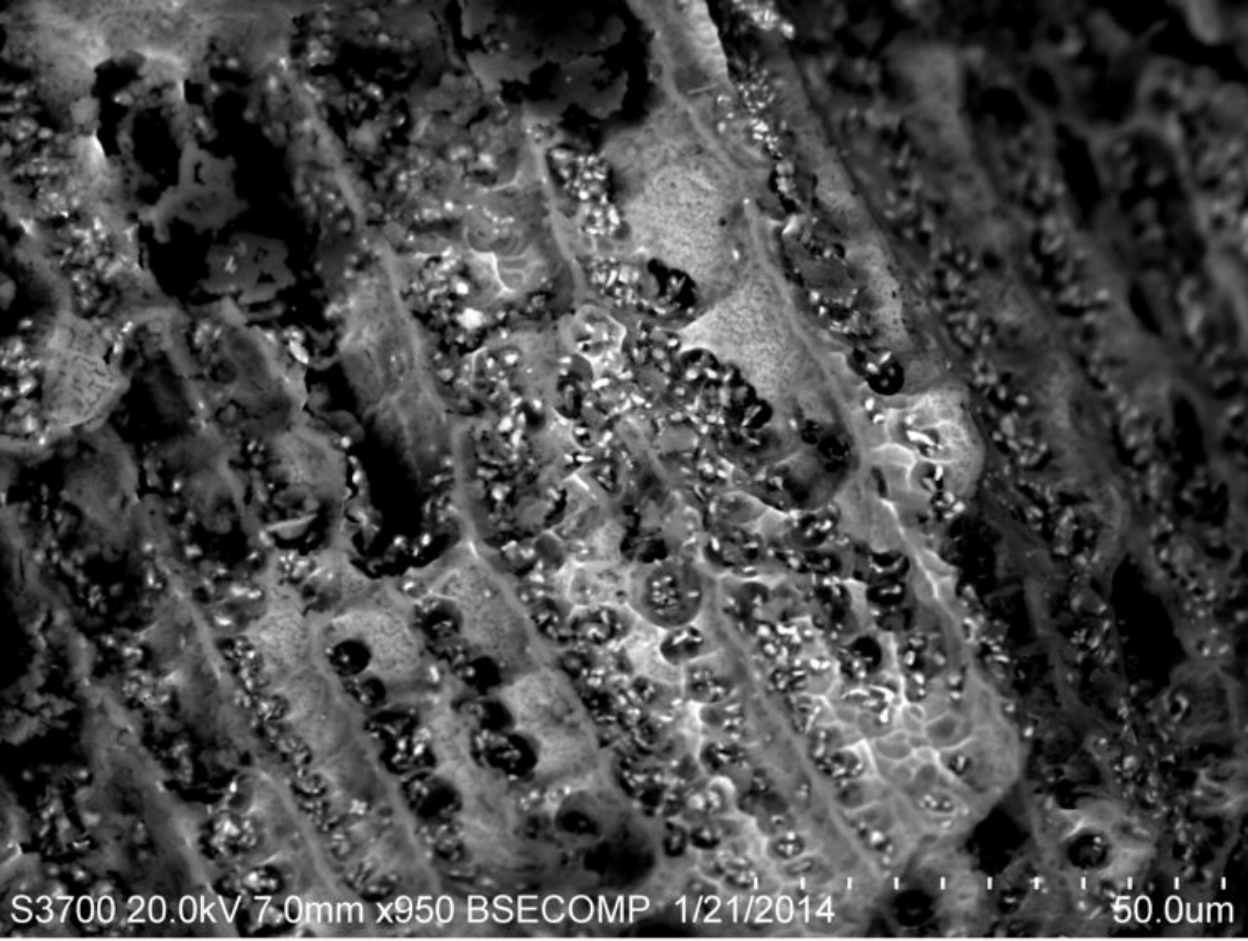

Fig. 18 - SEM fractograph of specimen 575B using backscattered electron (BSE) mode following electrolytic etch in oxalic acid. Note the bright particles on the fracture surface likely to be the precipitates observed previously. 